\title{
The case for cultural economic participation: achieving social and political change for Aboriginal peoples through community owned and run businesses
}

\author{
Sophie Hopkins
}

University of Technology Sydney, Faculty of Arts and Social Sciences, PO Box 123, Ultimo NSW 2007, Australia. sophie.hopkins@student.uts.edu.au

\begin{abstract}
Aboriginal community owned and run businesses have proven to instigate social and political change for Aboriginal communities in Australia, and the nation as a whole. Integral to this change is recognition of the enduring effects of colonisation and realisation of social, cultural and identity capital as valid forms of economic contribution.
\end{abstract}

Key words: Aboriginal; community owned businesses; economic participation; political change; social change

The social and political advancement of Aboriginal peoples in Australia has been constrained by the enduring process of colonisation which discriminates against and undermines the value of Aboriginal peoples. Aboriginal peoples have been dispossessed from cultural economic practices and excluded from the introduced settler-colonial economic model. Failure of the settler-colonial economic model to recognise contributions to the economic sector beyond economic capital or human capital has consequently undermined the contributions of Aboriginal community owned and run businesses. Aboriginal businesses provide suitable opportunities for engagement with the settler-colonial economic model where Aboriginal people can draw from, and strengthen, culture and identity. Social, identity and cultural capital contributions of Aboriginal businesses are closely related to instigation of social and political change. Aboriginal businesses generate economic participation-and improve social and political outcomes — of Aboriginal peoples through employment, supporting culture and identity, and investment within families and communities. In addition, economic participation increases revenue for Australian governments, by increasing the tax 
base, and reducing expenditure, particularly in the health and social security sectors, due to increased independence and improved socioeconomic outcomes.

Colonisation dispossessed Aboriginal peoples from their land, consequently separating Aboriginal communities from cultural economic practices. Cultural Aboriginal economic participation is characterised by complex systems of land management, production and trade; primarily, through nomadic foraging, that is, hunting and gathering (Jones et al. 2018, p. 1, Lloyd 2010, p. 25). Aboriginal culture and economic practices are inextricably connected to the land (Lloyd 2010, p. 25). However, this conflicts with the process of colonisation-which seeks to establish sovereignty over a territory - that requires removal of Aboriginal peoples from the land for expansion of colonies (Morris 1989, p. 7; Morris 1992, p. 73). Economic activities of colonisers reduced land available for Aboriginal communities, thereby disrupting cultural economic practices of Aboriginal peoples (Wolfe 2006, p. 388)._The settler-colonial economic model is characterised by land use and extraction, and development, described by Lloyd (2010, p. 26) as a 'distinctive form of capitalist regime'. Of note, this consists of agricultural practices. Agricultural practices were introduced to support the growth of colonies; a practice which, unlike the practices of the traditional owners of the land, is sedentary (Wolfe 2006, p. 295).

Morris $(1989,1992)$ establishes representation of Aboriginal peoples as the 'other' as a 'constitutive form of violence' relating to colonisation (Morris 1992, p. 73). Constructs of the Aboriginal identity situated Aboriginal people as inferior, (Morris 1992) justifying 'elimination of the native' (Wolfe 2006, p. 389). These identities were produced by those who sought sovereignty and was 'part of the political act of colonialism' (Morris 1989, p. 7, Morris 1992, p. 73). The fictional construct of Aboriginal peoples as the 'other' authorised a culture of terror which involved massacres and dispossession of Aboriginal peoples from their land (Morris 1989; 1992). Morris states these representations 'established knowledge and imposed truth which was inseparable from the exercise of the power on the colonial frontier' $(1989$, p. 30).

The ongoing process of colonisation, and its effects, are exemplified through the high rates of labour market discrimination experienced by Aboriginal peoples. Labour market discrimination is exclusion from the dominant economic system - that is, the settler-colonial model - which, unlike Aboriginal cultural economic models, focuses on income and acquiring wealth through waged labour. Racism against Aboriginal peoples has been prefaced by a history of legislative provisions which sought to eliminate and alienate Aboriginal peoples from society (Martin 2005, p. 108). These discriminatory policies have led to persistent exclusion and disadvantage of Aboriginal peoples in Australian society (Martin 2005, p. 128). Aboriginal and Torres Strait Islander peoples have lower rates of labour force participation compared to the Australian population's average (58 per cent and 65.9 per cent, respectively) (ABS 2016, 2019). Of those participating in the labour force, 46 percent of Aboriginal and Torres Strait Islanders are employed compared to 62.5 percent for the total Australian population aged 15 and over (ABS 2016; 2019). In addition, unemployment of Aboriginal and Torres Strait Islander peoples is more than four times the 
rate for the general population (20.6 per cent compared to 5.1 per cent, respectively) (ABS 2016; 2019). Aptly argued by Keen, exclusion from the dominant economic model is a deliberate act which alienates Aboriginal peoples from Australian society, causing dependency on government welfare payments and thus limiting 'political mobilization and autonomy' (2010, p. 7).

The dominant economic model fails to consider forms of capital other than economic and human capital (McRae-Williams et al. 2016, p. 13). The settler-colonial economic model is based on human capital theory. Human capital theory argues 'individual investment in knowledge and skills is motivated by a reward in the form of a return on investment or economic benefit' (McRae-Williams et al. 2016, p. 4; citing Becker 1993). However, such reward - and consequent measures of economic participation - does not align with the motivations of many Aboriginal peoples. Specifically, whilst the dominant economic model focuses on gain of wealth, many Aboriginal peoples seek belonging, identity, community and connection to country and culture (McRae-Williams et al. 2016, p. 14). McRae-Williams et al. argue that the settler-colonial economic model fails to acknowledge and recognise the value of land, language and culture unless they 'produce direct economic benefit' (2016, p. $18)$.

Solely valuing economic participation through financial gain or economic capital and human capital undermines the contributions of Aboriginal peoples who utilise cultural economic activities to engage with the dominant economic model. An individual's economic participation is not always financial capital or human capital; social capital, identity capital and cultural capital also contribute to generation of wealth and labour market productivity (McRae-Williams et al. 2016, p. 10). McRae-Williams et al. argue the settler-colonial economic model does not engage with different forms of capital as such forms of capital are viewed as problematic because they oppose the neoliberal ideology that informs economic policy in Australia (2016, p. 14). Failure to recognise and acknowledge alternate contributions results in a deficit discourse surrounding the economic participation of Aboriginal peoples which perpetuates labour market discrimination (PricewaterhouseCoopers Indigenous Consulting \& PricewaterhouseCoopers Consulting (PwC) 2018, p. 6).

Evidently, participation in the settler-colonial economic model is problematic for many Aboriginal peoples. Colonisation has forced many Aboriginal communities to engage with an economic model in a way which does not align with cultural values and practices. The process of hybridization has been used as a strategy for survival, and social and political change, amongst Aboriginal communities (Lloyd 2010, p. 31). Hybridization refers to the integration of elements of the settler-colonial economy into cultural economic models (Lloyd 2010, p. 29). Aboriginal businesses are a key means of engagement with the dominant economic model as they allow for alternate participatory activities as opposed to mainstream pathways which have been found to fragment Aboriginal identities and undervalue contributions of Aboriginal peoples (McRae-Williams et al. 2016, p. 15; Martin 2005, p. 126; PwC 2018, p. ii). Aboriginal run and owned businesses provide avenues for economic participation where ties to land and cultural economic practices are strengthened and labour 
market discrimination is reduced. Aboriginal businesses allow cultural Aboriginal economic participation to be recognised by dominant economic model indicators and consequently the value of Aboriginal peoples to Australia realised. Expansion of the Aboriginal business sector is driven by motivations to find alternative opportunities for employment, to provide for families and communities, to fill a gap in the service market, as well as an increase in government, and community funded programs promoting cultural Aboriginal economic participation (PwC 2018, p. i). Economic participation through Aboriginal controlled organisations, with effective and responsible leadership, can instigate social and political change for Aboriginal peoples, their community, and the nation as a whole (Martin 2005, p. 126).

Contributions of cultural economic participation initiatives must be realised. Aboriginal businesses employ more than thirty times more Aboriginal people compared to nonAboriginal businesses (PwC 2018, p. 19). Employment in an Aboriginal business not only allows cultural Aboriginal economic participation in the dominant economic model, but it also improves socioeconomic outcomes (Australian Institute of Health and Welfare (AIHW) 2016, p. 129). Employment reduces the gap between employment of Aboriginal and Torres Strait Islander and non-Indigenous Australians (PwC 2018, p. ii). More so, employment is a social determinant of health (AIHW 2016, p. 129). The World Health Organisation (WHO) recognises social determinants - including income, education, employment and social capital - as 'causes of the causes'; that is, social determinants influence health determinants and subsequently health outcomes (AIHW 2016, p. 129). Employment enables individuals to support themselves, their families and their communities. Importantly, income provides economic independence and development of autonomy; further, it allows for engagement through the purchase of goods and services.

Culture is an integral component of health for many Aboriginal Australians (Jones et al. 2018 , p. 2). Health and wellbeing are understood as holistic processes which includes physical, social, emotional and cultural factors (Jones et al. 2018, p. 2; Schultz et al. 2018, p. 2). Increased cultural engagement - that is, activities with culture and Country - is strongly linked to improved health outcomes, including reduction in health risk factors (Jones et al. 2018, p. 2; Schultz et al. 2018, p. 1). Using cultural knowledge and practices in business, and employment, strengthens identity and culture for all Aboriginal peoples involved: the business owner/s, employee/s, and communities (Jones et al. 2018; Schultz et al. 2018; PwC 2018). Aboriginal and Torres Strait Islander peoples own or control between 20 and 40 per cent of Australia's land (PwC 2018, p. 11). Cultural connection to land, as well as ownership and control, has led to establishment of employment in Indigenous Land Management and Ranger roles (Jones et al. 2018; PwC 2018, p. 11; Schultz et al. 2018). Employment in these roles invites Aboriginal employees to draw from cultural as well as contemporary knowledge to manage lands and seas (Schultz et al. 2018, p. 2). Such roles have been noted in the literature as successful employment practices for achieving social and political change by affirming culture and identity and improving health and wellbeing (Jones et al. 2018; Schultz et al. 2018). 
Benefits of Aboriginal businesses have been found to substantially outweigh cost and have high social return on investment (SROI) outcomes (PwC 2018, p. 20). Again, this reinforces economic participation should not be restricted to acquisition of income and wealth. Social return on investment (SROI) calculates a monetary value of social impact and compares this with the cost of that benefit (Hudson 2016, p. 4; PwC 2018, p. 20). Further benefits, acknowledged by SROI analysis, include strength and pride within families and communities, connection to culture, support of dependents in obtaining secondary and tertiary education, gain finance and management skills, and strengthen community and individual governance and autonomy (PwC 2018, p. 19-20).

Aboriginal businesses, as a form of economic participation, instigate social and political change through investment in families and communities - preserving and extending social and political development. Noel Pearson is noted for arguing Aboriginal cultural economic models 'demanded responsibility' and 'reciprocity', whilst the settler-colonial economic model is an 'artificial economy' with 'no responsibility or reciprocity' (Pearson 2011, p. 143). As such, the introduced economy 'has undermined Aboriginal law' and 'traditional values and relationships' (Pearson 2011, p. 143). It may be argued that the sustained cultural values, and systems of kinship, have led to the tendency to invest. PricewaterhouseCoopers reported Aboriginal businesses 'reinvested asset generation into their businesses to provide increased business and family stability' (PwC 2018, p. 19). Aboriginal businesses also use other Aboriginal businesses within their supply chain to 'invest back into their communities' by generating employment and demand for supply in other businesses (PwC 2018, p. iii, 5). In addition, Aboriginal trusts invest in 'community development opportunities (such as education scholarships) for development opportunities that promote stability and an improved quality of life now and for future generations' (PwC 2018, p. 20).

Financial contribution of the Indigenous (Aboriginal and Torres Strait Islander peoples) business sector to Australia's economy is substantial, overlooked and undervalued. PricewaterhouseCoopers estimated the total economic contribution of the Indigenous business sector to Australia's economy in 2016 to be between $\$ 2.2$ and $\$ 6.66$ billion (PwC 2018, p. iii). This is equivalent to 0.1 to 0.4 per cent of Australia's Gross Domestic Product (GDP) (PwC 2018, p. iii). This contribution has been absent from narratives around Australia's economic history and economic participation of Aboriginal peoples (PwC 2018, p. I, citing Keen 2010, p. 1).

Lastly, engagement of Aboriginal peoples with the dominant settler-colonial economy, in their own ways such as through Aboriginal businesses, increases economic independence and improves socioeconomic outcomes; thus, increasing revenue and decreasing expenditure in government budgets (Deloitte Access Economics 2014, p. i). Revenue from government budgets is restricted by reduced economic participation of Aboriginal Australians compared to the Australian average. This loss is associated with, but is not limited to, the incompatibility of Aboriginal activities with the dominant economic model, shorter life expectancy, social exclusion, and labour market discrimination (AIHW 2016, p. 4). In addition, government budgets include expenditure in other sectors, such as health and social security, to address disadvantage (Deloitte Access Economics 2014, p. 1). Deloitte Access 
Economics estimate that improving Aboriginal outcomes to match the Australian average by 2031 would result in a net gain of $\$ 11.9$ billion for Australian governments (Deloitte Access Economics 2014, p. i). This is attributed to a larger economy and consequently a larger tax base for a $\$ 7.2$ billion increase in revenue; in addition, improved income and wealth would see a reduction in health and social security costs of a total $\$ 4.7$ billion (Deloitte Access Economics 2014, p. ii).

Participation of Aboriginal peoples in Australia's settler-colonial economy would instigate social and political change, leading to improved socioeconomic outcomes. However, Aboriginal peoples must be supported to engage in ways which suit them and are appropriate. Failure to recognise social, identity and cultural capital contributions to Australia's economy inhibits social and political development in Australia. Recognition of alternate forms of capital would acknowledge and support the value of Aboriginal peoples. Aboriginal businesses have proven to be effective in generating economic participation of Aboriginal peoples. Businesses run and owned by Aboriginal peoples boost employment for Aboriginal peoples, strengthen Aboriginal culture and cultural identities, and invest in families and communities. Further, Aboriginal businesses increase revenue and reduce expenditure for Australian governments. Overall, economic participation allows individuals to develop economic independence and autonomy, which results in improved outcomes.

\section{References}

Australian Bureau of Statistics 2019, Labour Force, Australia, May 2019, cat no. 6202.0, ABS, Canberra, viewed 15 June 2019, <https://www.abs.gov.au/ausstats/abs@.nsf/Latestproducts/6202.0Main\%20Features2May\% 202019? opendocument\&tabname $=$ Summary \&prodno=6202.0\&issue $=$ May\%202019\&num $=$ \&view $=>$.

Australian Bureau of Statistics 2016, National Aboriginal and Torres Strait Islander Survey, 2014-15, cat. no. 4714.0, ABS, Canberra, viewed 15 June 2019, < https://www.abs.gov.au/ausstats/abs@.nsf/Lookup/by\%20Subject/4714.0 201415 Main\%20Features Labour\%20force\%20characteristics 6>.

Australian Institute of Health and Welfare 2016, Australia's health 2016, cat. no. AUS 199, Australian Government, Canberra, <https://www.aihw.gov.au/getmedia/9844cefb-77454dd8-9ee2-f4d1c3d6a727/19787-AH16.pdf.aspx?inline=true>.

Deloitte Access Economics 2014, Economic benefits of closing the gap in Indigenous employment outcomes, Sydney, <https://www2.deloitte.com/content/dam/Deloitte/au/Documents/finance/deloitte-au-faseconomic-benefits-closing-gap-10-feb-2014-240914.pdf>. 
Dockery, M. \& Lovell, J. 2016, 'Far removed: An insight into the labour markets of remote communities in Central Australia', Australian Journal of Labour Economics, vol. 19, no. 3, pp. 145-174.

Hudson, S. 2016, 'Awakening the 'sleeping giant': The hidden potential of Indigenous businesses', Policy, vol. 32, no. 1, viewed 12 June 2019, <https://www.cis.org.au/app/uploads/2016/04/32-1-hudson-sara1.pdf>.

Jones, R., Thurber, K.A., Wright, A., Chapman, J., Donohoe, P., Davis, V. \& Lovett, R. 2018, 'Associations between Participation in a Ranger Program and Health and Wellbeing Outcomes among Aboriginal and Torres Strait Islander People in Central Australia: A Proof of Concept Study', International Journal of Environmental Research and Public Health, vol. 15 , no. 7, pp 1478-1491.

Keen, I. 2010 'Introduction' in I. Keen (ed.) Indigenous participation in Australian economies: historical and anthropological perspectives, ANU E Press, Canberra, pp. 1-22.

Lloyd, C. 2010 'The emergence of Australian settler capitalism in the nineteenth century and the disintegration/integration of Aboriginal societies: hybridisation and local evolution within the world market' in I. Keen (ed.) Indigenous participation in Australian economies: historical and anthropological perspectives, ANU E Press, Canberra, pp. 23-39.

Martin, D. F. 2005, 'Rethinking Aboriginal Community Governance' in P. Smyth, T. Reddel $\&$ A. Jones (eds) Community and Local Governance in Australia, University of New South Wales, Sydney, pp. 108-127.

McRae-Williams, E., Guenther, J., Jacobson, D. \& Lovell, J. 2016, 'What are the enablers of economic participation in remote and very remote Australia, and how can we identify them?', Learning Communities: International Journal of Learning in Social Contexts, vol. n/a, no. 19, pp. 6-25.

Morris, B. 1989, 'Colonial Domination as a Process of Marginalisation', Domesticating Resistance: the Dhan-Gadi Aborigines and the Australian State, Berg, Oxford, pp. 6-30.

Morris, B. 1992, 'Frontier Colonialism as a Culture of Terror', Journal of Australian Studies, vol. 16 , no. 35 , pp. $72-87$.

Pearson, N. 2011, Up from the mission: Selected writings, 2nd edn, Black Inc., Melbourne.

PricewaterhouseCoopers Indigenous Consulting \& PricewaterhouseCoopers Consulting 2018, The contribution of the Indigenous business sector to Australia's economy, PwC, Australia, < https://www.pwc.com.au/indigenous-consulting/assets/the-contribution-of-theindigenous-business-sector-apr18.pdf $>$. 
Schultz, R., Abbott, T., Yamaguchi, J. \& Cairney, S. 2018, 'Indigenous land management as primary health care: Qualitative analysis from the Interplay research project in remote Australia', BMC Health Services Research, vol. 18, viewed 5 June 2019, <https://bmchealthservres.biomedcentral.com/articles/10.1186/s12913-018-3764-8>.

Wolfe, P. 2006, 'Settler colonialism and the elimination of the native', Journal of Genocide Research, vol. 8, no. 4, pp. 387-409. 